\title{
ARQUITETURA VERNACULAR E PAISAGEM AMAZÔNICA: UM CAMINHO NA BUSCA PELO HABITAR POÉTICO
}

\author{
Vernacular Architecture and the Amazon Landscape: a Path in Search of a Poetic Dwelling \\ Arquitectura Vernácula y el Paisaje del Amazonas: un Camino en Busca del Habitar Poético \\ Laelia Regina Batista Nogueira
}

\begin{abstract}
Resumo: Relatar uma pesquisa é o principal objetivo deste texto. Tal pesquisa refere-se à dissertação de mestrado (Programa de Pós Graduação em arquitetura e Urbanismo - UFF) se desenvolveu em um dos lugares no qual o imaginário humano invade as profundezas da Terra. Assim a Amazônia é o lugar no qual o fenômeno estudado se revelou: o habitar poético através do qual o ribeirinho se "de-mora" sobre a Terra, travando com ela uma relação visceral. Tomando como abordagem metodológica os princípios fenomenológicos, é com base na ontologia Heideggeriana e tendo a poética de Bachelard como meio de abertura para o mundo, que o trabalho se desenrola, e apresenta assim a maneira como o povo ribeirinho no Amazonas habita, habitar esse que podemos ver revelado através da materialidade de suas casas - de sua arquitetura - compondo e completando a paisagem que os cerca e os invade por completo.
\end{abstract}

Palavras-chave: Fenomenologia; Amazônia; Habitar; Arquitetura; Ribeirinho.

Resumen: Informará de la búsqueda es el objetivo principal de este texto. Esta investigación se refiere a la tesis de maestría (Programa de Graduados en Arquitectura y Urbanismo - UFF) se ha convertido en uno de los lugares en los que la imaginación humana invade las profundidades de la tierra. Así que Amazon es el lugar donde se reveló el fenómeno estudiado: el habitar poético a través del cual el río es-vivo en la Tierra, la captura de ella una relación visceral. Tomando como enfoque metodológico de los principios fenomenológicos com base en la ontología heideggeriana y tener la poética Bachelard como medio de apertura al mundo, el trabajo se desarrolla, y también lo ha hecho la forma en que las personas fluviales en la vida de Amazonas, habitan esto podemos ver revelado a través de la materialidad de sus hogares, -desde su Arquitectura-escritura y completar el paisaje que rodea e invade por completo.

Palabras-clave: Fenomenología; Amazonia; Habitar; Arquitectura; Ribeirinho.

Abstract: Report a search is the main objective of this text. This research refers to the master's thesis (Graduate Program in Architecture and Urbanism - UFF) has developed into one of the places in which the human imagination invades the depths of the earth. So Amazon is the place where the studied phenomenon was revealed: the poetic dwelling through which the river habitant is-live on Earth, catching her a visceral relationship. Taking as methodological approach the phenomenological principles proposed by Hurssel is based on Heideggerian ontology and having the Bachelard poetics as a means of opening to the world, the work unfolds, and so has the way the riverine people in Amazonas lives , inhabit this we can see revealed through the materiality of their homes, -from his Architecture-writing and completing the landscape that surrounds and invades completely.

Keywords: Phenomenology; Amazon; Dwell; Architecture; Riverside.

\section{Introdução}

Relatar uma pesquisa é o principal objetivo deste texto. Tal pesquisa refere-se à dissertação de mestrado que se desenvolveu em um dos lugares no qual o imaginário humano invade as profundezas da Terra, com a qual segundo Dardel o homem tem uma relação visceral. Assim a Amazônia é o lugar no qual o fenômeno estudado se revela: o habitar poético do ribeirinho e o modo com o qual se "de-mora" sobre a Terra. Mais especificamente no Amazonas, estado brasileiro, aonde se encontra boa parte da maior floresta equatorial do mundo: a floresta amazônica.
O trabalho foi realizado através do mestrado, subsidiado na Universidade Federal Fluminense, no Programa de Pós-Graduação em Arquitetura e Urbanismo, orientado pelo Prof. Dr. Werther Holzer, tendo como título "Entre idas e vi(n)das do rio: o habitar poético do ribeirinho no Amazonas". Tomando como abordagem metodológica os princípios fenomenológicos, é com base na ontologia Heideggeriana e tendo a poética de Bachelard como meio de abertura para o mundo que o trabalho se desenrola, apresentando a maneira como a população ribeirinha, população tradicional das margens dos rios no Amazonas habita. É através da materialização da sua forma de pensar, da construção das suas casas, que o ribeirinho se relaciona com a paisagem e a completa. 
O ponto principal do trabalho é desvelar e entender a relação homem-mundo através da arquitetura apresentada a qual se integra e se revela na paisagem, e que sem o homem ela se tornaria incompleta. Como cita Dardel:

(...) a paisagem não é, em sua essência, feita para se olhar, mas a inserção do homem no mundo, lugar de um combate pela vida, manifestação de seu ser com os outros, base de seu ser social. (...) Uma verdade emerge da paisagem, contudo como teoria geográfica ou mesmo como valor estético, mas como uma fiel expressão da existência. (...) A paisagem pressupõe uma presença do homem, mesmo lá onde toma forma de ausência. Ela fala de um mundo aonde o homem realiza sua presença circunspeta e atarefada. (DARDEL, p. 32, 2011)

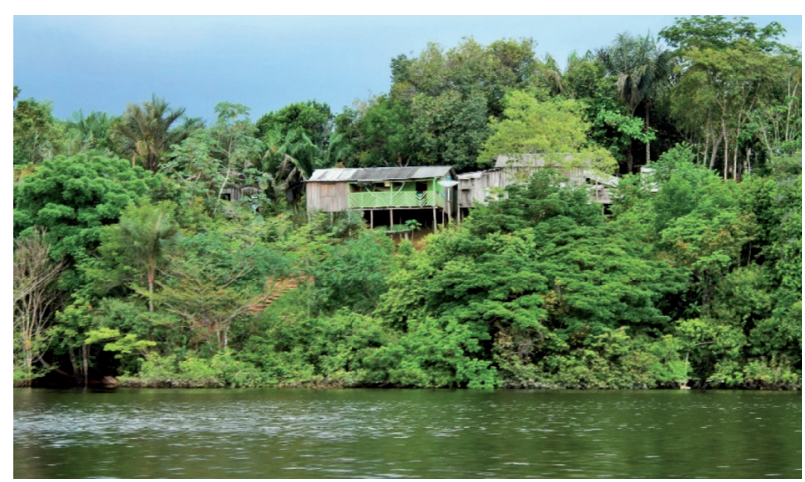

Figura 1: Casa e floresta se misturam, uma não é sem a outra. Fonte: Laelia Nogueira, Rio Cuieiras, terra firme, 2015.

A paisagem se torna fundamental na base desse trabalho, pois é a partir dela, que essa relação profunda experienciada através dos sentidos, constrói seu habitar, e consequentemente forma a quadratura heideggeriana. Desta maneira nos cabe olhar a Amazônia como ela realmente é: não homogênea e monótona como pode parecer, mas sim em suas diversas paisagens e posicionamento do homem em meio ao espaço que ele ocupa nesta região, sendo eles várzea, terra firme e o rio. Na Amazônia este último elemento é tudo:

Os rios na Amazônia constituem uma realidade labiríntica e assumem uma importância fisiográfica e humana excepcionais. O rio é o fato dominante nessa estrutura fisiográfica e humana, conferindo um ethos e um ritmo à vida regional. Dele dependem a vida e a morte, a fertilidade e a carência, a formação e a destruição de terras, a inundação e a seca, a circulação humana e de bens simbólicos, a política e a economia, o comercio e a sociedade. $\mathrm{O}$ rio está em tudo. (LOUREIRO, 1995, p. 121)

"O rio comanda a vida" como diz o autor Leandro Tocantins, no título de um de seus livros mais conhecidos.
Ele muda a paisagem entre suas cheias e vazantes e junto, muda a vida de quem habita em suas beiras, moldando suas margens e seus habitantes. Assim, nosso percurso envolverá: comunidades no Careiro da Várzea, região como o nome já fala de várzea; comunidades no rio Cuieiras, no baixo Rio Negro, rio de águas negras e áreas de terra firme; e a comunidade do Catalão, comunidade de casas flutuantes muito próximo do encontro das águas, famoso ponto turístico e de referência simbólica no estado do Amazonas. Para o caboclo ribeirinho entre terra e céu, há um rio. Portanto, buscaremos fazer um relato do percurso de trabalho, tomando como base a fenomenologia, principal abordagem que norteou o trabalho.

\section{Objetivos}

O presente texto busca relatar a pesquisa desenvolvida ao longo do mestrado, focando em como a fenomenologia foi fundamental para permitir que o trabalho se desenvolvesse, tomando como partido uma abordagem holística e transcendental do fenômeno estudado - o habitar e o seu revelar através da materialidade das casas -, não o olhando como um problema de pesquisa, visto que não há um problema para se resolver, mas sim um mundo para se revelar. Também podemos listar como objetivos do trabalho, trazer o olhar do leitor para uma realidade cotidiana de uma certa população, na qual não devemos olhá-la de uma maneira capitalista e globalizada como aprendemos a fazer, reconhecendo qualquer outro tipo de manifestação cultural apenas partir das nossas próprias experiências como se elas fossem determinantes para todas as maneiras de se viver, mas sim, olhá-la como ela é: uma cultura tradicional riquíssima, e com uma relação profunda entre homem e mundo.

Desta maneira, entendemos que a contribuição deste trabalho está relacionada com um retorno a valorização do ser em detrimento do ter, onde um não condiciona o outro. Aqui nosso foco está na arquitetura vernacular construída nessas áreas de várzea, terra firme e sobre o rio. Como diz Holzer: "Arquitetura produzida na região, que tem como características vinculadas as atividades econômicas e ao ambiente físico onde está situada. Tais características são geradas por uma paisagem que também a geram (...)" (HOLZER, WERTHER, p. 161, 2008).

Entender como se habita é se autoconhecer. O conhecimento nos permite ser-no-mundo a partir da relação visceral já citada anteriormente, mencionada por Eric Dardel (2011), compreendendo assim a relação entre céu, terra, mortais e divino, descritos na quadratura heideggeriana e como eles se reúnem na forma de casa e se expressam na sua materialidade. Ainda, ser-no-mundo nos permite pensar em como construir nosso canto no mundo, nosso microcosmo, como afirma Gaston Bachelard (1996), para que possamos poeticamente habitar a Terra. Podemos as- 
sim chegar à uma arquitetura fenomenológica que busque esse reencontro com o habitar e consequentemente com o próprio ser, através de uma fenomenologia do ambiente cotidiano como propõe Christian Norberg-shullz (1995), que podemos exemplificar a partir de Heidegger, quando fala do ato de construir e da relação desse construir com o lugar e a paisagem:

A insistência da capacidade de deixar terra e céu, divino e mortais serem, com simplicidade, nas coisas. Essa capacidade situou a casa camponesa na encosta da montanha, protegida contra o vento e contra o sol do meio dia, entre as esteiras dos prados na proximidade da fonte. Essa capacidade concedeu-lhe o telhado de madeira, o amplo vão, inclinação íngreme das asas do telhado a fim de suportar o peso da neve e de proteger suficientemente os cômodos das longas tormentas das noites de inverno. Essa capacidade não esqueceu o oratório atrás da mesa comensal. Deu espaço aos lugares sagrados que são o berço da criança e a "árvore dos mortos", expressão usada ali para designar o caixão do morto. Deu espaço aos vários quartos, prefigurando, assim, sob um mesmo teto, as várias idades de uma vida, no curso do tempo. Quem construiu a casa camponesa foi um trabalho das mãos surgido ele mesmo de um habitar que ainda faz uso de suas ferramentas e instrumentos como coisas. (HEIDEGGER, p. 9-10, 2002)

\section{Método: deixando o mundo entrar}

O trabalho foi desenvolvido de maneira que seus caminhos pudessem se revelar a partir de seu próprio percurso, portanto, houve um trabalho inverso: o trabalho foi dividido em duas etapas: na primeira, utilizamos o trabalho de campo, no qual pudemos voltar intencionalmente para o lugar que iríamos experienciar para, em seguida, pudesse fazer as relações com as teorias propostas, pelas referências teóricas nas quais gostaríamos de embasar o trabalho.

Ao longo da dissertação, podemos perceber uma profunda mescla entre campo e teoria, buscando quebrar com as dualidades do mundo, permitindo uma epoché mais intensa, na medida em que foi permitido a nós olhar em volta, tomando como referencial a própria vida dos moradores daquela região, compreendendo como disse seu Olavo, comandante de embarcação responsável por nossos percursos no rio Cuieiras: "Pra mim não tem essa coisa de ser mais sabido. O que conta é a experiência que você tem. Cada um sabe uma coisa mais que o outro” (Comunicação pessoal. "Seu Olavo”, 2015, Rio Cuieras, cheia.)

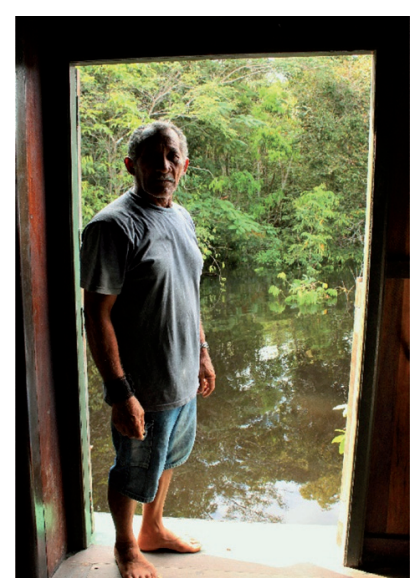

Figura 2: Seu Olavo. Fonte: Laelia Nogueira, Rio Cuieiras, 2015.
Assim, utilizou-se os aportes metodológicos nos quais a fenomenologia se baseia, tais como: intencionalidade, descrição, redução e intersubjetividade; buscando desapegar de conceitos pré-estabelecidos sobre o tema de pesquisa para que pudéssemos ver o mundo como ele realmente se apresenta. Dessa forma foi possível perceber o encantamento pelos lugares os quais passamos, reconhecendo-os como lugares de vida, lugares de gente, as quais demos voz através de conversas nas quais pude entender diversos dos aspectos cotidianos de suas vidas e suas relações com o meio que os cercam.

Para buscar uma apresentação do lugar/paisagem na qual estávamos inserida, o mais próximo do real possível, utilizei-me da fotografia, a fim de captar momentos percebidos e gerar a ambiência do local descrito, ajudando a contar a história, mesclando com as descrições feitas por cientistas e por escritores literários, referenciando à Maurice Merleau-Ponty que diz que "a verdadeira filosofia é reaprender a ver o mundo, e nesse sentido uma história narrada pode significar o mundo com tanta profundidade quanto um tratado de filosofia" (MERLEAU-PONTY, 1996, p. 19).

Entendemos aqui a epoché e a abertura para o mundo como fundamental para o andamento deste trabalho, pois, com a visão fechada para o mundo-da-vida acabaria alienada pela técnica, não me permitindo, assim, ver o mundo como um todo. Deixamos então, que o processo acontecesse conforme o ritmo das águas, que guiam as embarcações por entre seus braços e margens, buscando sempre uma relação intersubjetiva e quiçá afetiva com os lugares que estivemos, afetividade sem a qual não seria possível o entendimento do lugar a partir de uma perspectiva não dual, pois a falta de afeto provavelmente me guiaria para um caminho mais rígido e duro, o qual em nada se relaciona com o ritmo de vida do ribeirinho. Então, assim como se retira os sapatos antes de se adentrar em uma casa ribeirinha (Figura 3), também nos despimos antes de adentrar no seu mundo. 


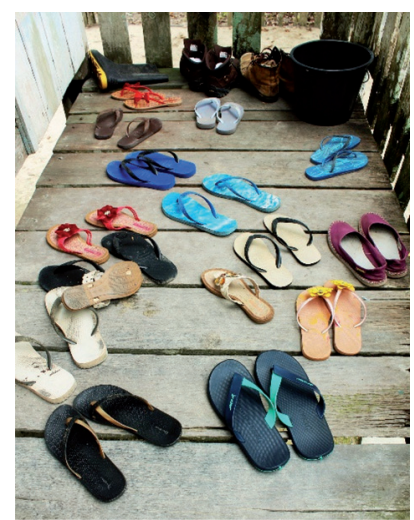

Figura 3: Tirando os sapatos.

Fonte: Laelia Nogueira, 2015 .

\section{0 caminhar da pesquisa}

Impossível seria não se encantar com a paisagem a baixo (Figura 4):

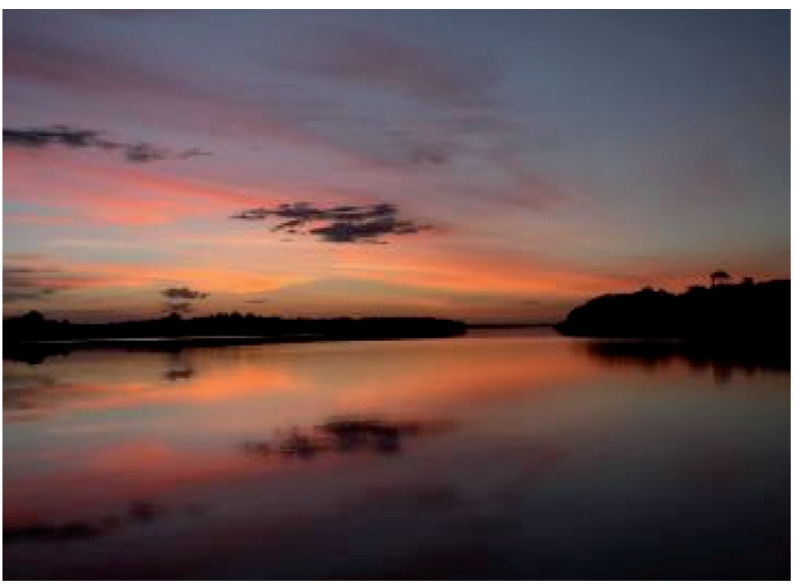

Figura 4: Pôr-do-sol no rio Cuieiras. Fonte: Laelia Nogueira, 2015.

A magnitude nos envolve e nos faz divagar sobre nossa própria existência. Seria impossível viver nesse mundo sem entregar-se a ele, sem entregar-se ao seu mistério e a sua profundidade:

Ela (a floresta) preenche o espaço, envolve o homem em mistério e temor (...) A floresta comunica ao espaço sua profundidade e seu silencio. Obscuridade solene sonoridade sufocada que amplifica o menor barulho, misteriosa quando a luz, peneirada, filtrada em raios, vem se lançar sobre seus sub-bosques, ela assombra a imaginação dos homens, favorece sua sensibilidade e meditação. (DARDEL, 2011)

A presença do mundo aqui é tão intensa que podemos obter diversas percepções sobre a relação casa-homem-mundo: observamos como todos estão inteiramente ligados de uma maneira intersubjetiva, onde um forma 0 outro e é por esse também formado, pois um extrapola o limite do outro, mostrando que esses limites na realidade não existem. Observando a imagem a seguir (Figura 1), percebemos um garoto executando a tarefa de lavar louça. Essa tarefa, entretanto, não é feita do lado de dentro da casa, mas sim fora, na beira do rio, sobre um suporte de maneira que pode ser chamado de "jirau", nos mostrando como a casa ultrapassa as paredes da própria construção e a casa deixa de ser meramente uma construção para se tornar o mundo inteiro.

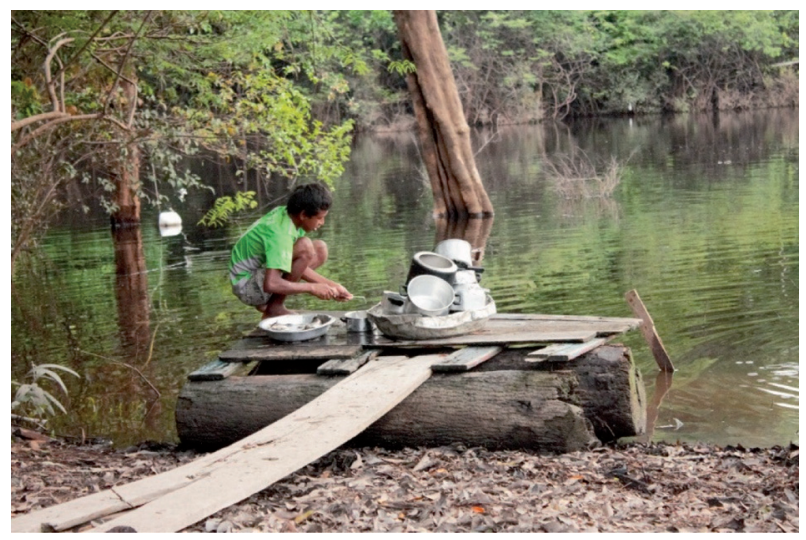

Figura 5: Menino lavando louça. Autor: Laelia Nogueira, Rio Cuieras Maio 2015.

A partir dessa foto podemos observar essa relação de convivência com a natureza: as casas seguem quase sempre cercadas pela vegetação, que está em uma escala muito maior que a humana. A utilização do ambiente, não apenas como recurso - para o transporte; lavar louças e roupas; comer ou beber - mas principalmente como base e meio de toda a realização, como diz Dardel. (p. 32, 2011). Esse é um aspecto comum que podemos perceber nas comunidades, sejam de várzea, terra-firme ou flutuantes.

Assim, percebemos uma vida de troca e respeito constante entre homem e Terra. Com a Terra o homem se entende de imediato (DARDEL, p. 120, 2011) Como Loureiro podemos exemplificar essa relação para os amazônidas:

Neste estudo da cultura amazônica, leva-se em conta uma cultura presente na atualidade regional, num momento em que homens ainda não se separaram da natureza, onde perdura ainda uma harmonia mesmo entrelaçada de perigos, e se vive em um mundo que ainda não foi dessacralizado; onde o coração vive ardoso do espírito das origens e onde brota ainda aquele leite e mel das sagradas origens. Onde os mistérios da vida se expõe com naturalidade e o numinoso acompanha as experiências dos outros e de si mesmo. (LOUREIRO, 1995, p. 16)

Ainda, Loureiro também afirma que a estética amazônica é extremamente simétrica assim como a paisagem com a qual o ribeirinho convive diariamente, isso se reflete na sua arquitetura como podemos perceber na imagem a seguir Figura 6). 


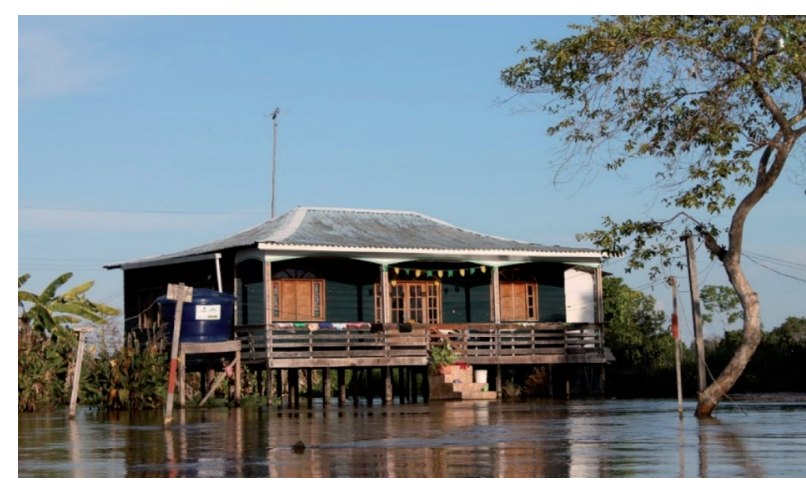

Figura 6: Casas “de campo”, Miracauera, Careiro da Várzea, Laelia Nogueira, Julho de 2014.

A casa a cima (Figura 6) é uma casa localizada na comunidade do Miracauera, localizado em área de várzea no município do Careiro da Várzea. Essas casas são casas denominadas pelos moradores como "casa de campo". Ao observá-las e pensarmos nesse nome podemos facilmente relacioná-las com uma casa típica da colonização portuguesa, que se espalhou por todo o Brasil, inclusive, vemos isso fortemente quando observamos sua planta-baixa.

No Amazonas esse modelo de casa, talvez seja um dos modelos mis usuais devido à grande migração de nordestinos, com raízes portuguesas que se instalou no Amazonas atrás de melhores condições de vida. $\mathrm{O}$ que podemos perceber então é a mescla de diversas culturas, por exemplo, da estética e da noção de casa a partir das casas de campo, com os materiais disponíveis na região, e respeitando seu ciclo, de cheias e vazantes do rio, tornando-as então suspensas por esteios, o que as tornam palafitas.

Durante as cheias dorme-se ouvindo os barulhos intensos da vida em abundancia que ali se desenvolve. A água corrente é constante; sapos e peixes que saltam, grilos e cigarras que cantam. As aranhas fazem suas teias rapidamente entre os suportes da maromba construída para ser o caminho entre a embarcação e a casa. Alberto Rangel conta-nos que: "À hora do meio-dia ensoalhado, a floresta é pavorosamente muda; à noite, ela é wagnerianamente agitada de todas as vozes. Vozes que vão do clamor insano d'almas errando em assombro de desespero" (RANGEL, 2008, p. 40).

Nessa região de várzea a população em geral vive da agricultura ou da pecuária - o gado fica na propriedade do seu dono durante a vazante, e nos períodos de cheias esses são transferidos para áreas de terra firme onde, ou proprietário dos bois paga uma taxa por cabeça, ou são construídos currais suspensos que possam acomodar os bois durante esse período. Nessa região, são poucas as pessoas que vivem do extrativismo de especiarias amazônicas - desde madeiras a frutos mais exóticos -, portanto alguns conhecimentos sobre as matérias primas da região já se perderam.

Esse é um ponto importante, pois reflete diretamente na arquitetura produzida. Como podemos perceber na fi- gura 06 e também na Figura 7, as tábuas de madeira utilizadas são em geral dispostas na horizontal, devido ao seu encaixe macho-fêmea. Essas madeiras são normalmente compradas já com os cortes e encaixes, e não retiradas diretamente da natureza por seus moradores.

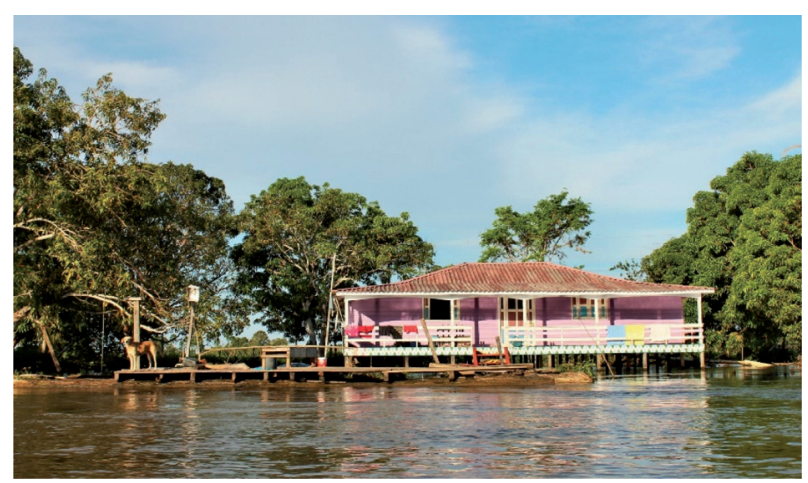

Figura 7: Casa. Miracauera Careiro da Várzea, rio Solimões. Fonte: Laelia Nogueira, 2014.

As casas de várzea possuem um caráter interessante que é o da sua desmontagem e montagem em outro lugar. Isso se dá com uma determinada frequência devido a algumas características determinadas também pelas mudanças sazonais do rio. Entre cheias e vazantes, as terras são levadas e trazidas por toda a parte. A terra sede de um lado para se remodelar no outro. A terra cai aqui para se reerguer ali. "É a cobra grande fazendo seu ninho", diria o caboclo. Quando o ribeirinho percebe, através da leitura do mundo, que a terra está próximo a ceder, ele desfaz a sua casa - assim como a terra será desfeita- e a reergue em outra parte do terreno- assim como a terra que caiu encontrará um novo local para instalar-se.

A casa é desmontada, mas jamais completamente desfeita, visto que a nova casa que irá se erguer é sempre quase idêntica à anterior, demonstrando afeto pela casa, consequentemente a importância simbólica daquela estrutura. Os que podem, melhoram-na com outra pintura ou uma pequena ampliação, mas em geral a disposição dos ambientes ou sua forma, permanecem a mesma da anterior. Nas imagens abaixo (Figura 8; Figura 9) podemos ver a diferença entre os níveis da água na cheia e na vazante:

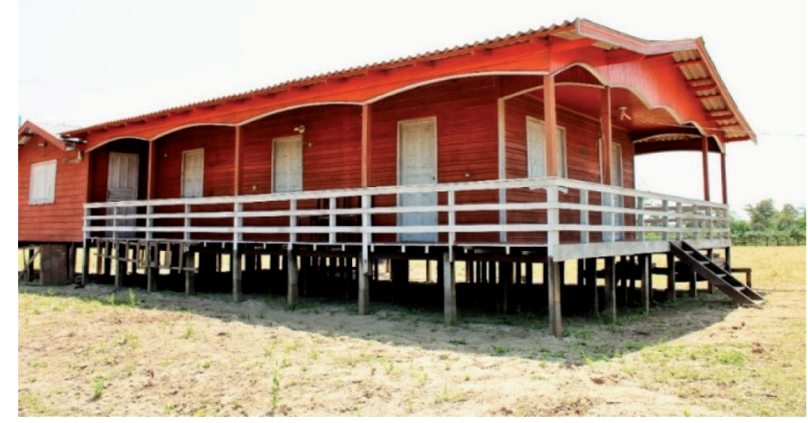

Figura 8: Casa de vázea na seca Miracauera, Careiro da Várzea, Laelia Nogueira, setembro de 2014. 


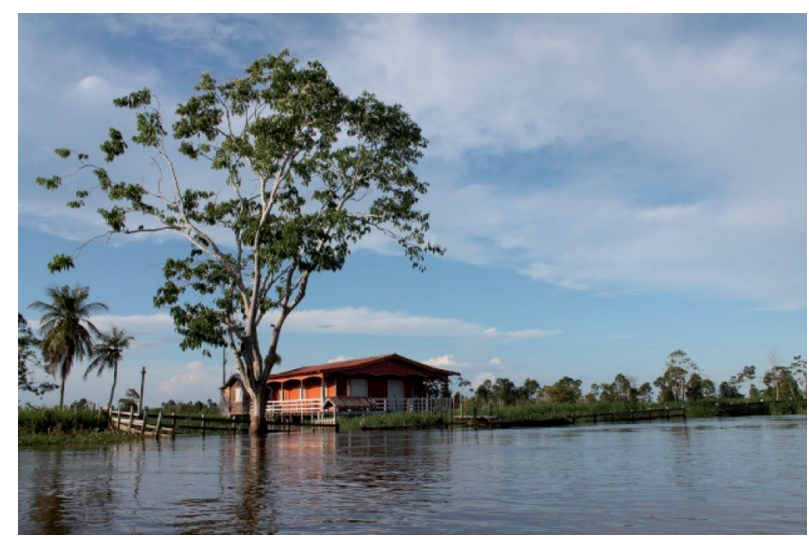

Figura 9: Casa de várzea na cheia, Miracauera, Careiro da Várzea, Laelia Nogueira, Julho de 2014.

Muitas vezes a casa nem chega a ser desmontada, ela tem seus esteios cortados e essa é transferida através de uma espécie de trilho de madeira para mais distante da beira diminuído o risco de desabar junto com a terra que cai. Em caso de serem pegos desprevenidos e perderem suas casas o caboclo se ergue novamente como diz Alberto Rangel (p. 70, 2008), "No dia seguinte, a vítima era um vencedor, plantando no chão, no alto da terra caída, o esteio de sua nova habitação".

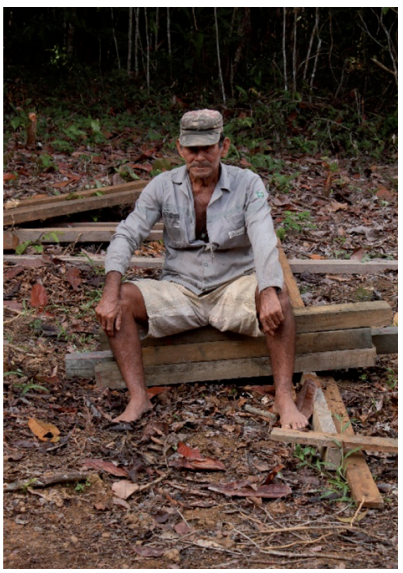

Figura 10: Seu Antônio. Imagem do ribeirinho. Fonte: Laelia Nogueira, 2015 .

Em outros casos quando se perde a propriedade inteira, o que é bem possível devido as grandes proporções das terras caídas, o caboclo encontra nos braços do rio seu alento e constrói o flutuante. Uma outra tipologia de casa muito comum na Amazônia. Essa é uma casa que como o nome já diz, ela flutua na água, sobre boias compostas por grandes toras de uma arvore típica da região de várzea, o Açacu. Uma madeira muito resistente, a qual apesar dessa sua propriedade ela também de capaz de boiar de maneira extremamente efetiva, possuindo alta durabilidade. Atualmente é uma madeira protegida, e que pode possuir um custo bastante alto, muitas fezes fora da realidade econômica dos ribeirinhos, que antes podiam extrair diretamente da natureza e que agora são muitas vezes obrigados a pagar.
O flutuante (Figura 11) é uma tipologia extremamente interessante de ser utilizada na Amazônia, já que ela tem o rio inteiro como seu lugar. É muito comum pessoas que vivem em flutuantes mudarem com frequência de lugar, já que sua casa pode ser rebocada com a ajuda de uma embarcação, essa, por sua vez é um item bastante comum entre os ribeirinhos em seus mais diversos portes, sendo comum que moradores de flutuantes tenham embarcações que consigam levar a casa. A ausência de muitos móveis também permite a leveza da casa o que auxilia no seu transporte.

Essas casas sobre balsas, possuem o mesmo formato e concepção que as casas de palafitas encontradas nas áreas de várzea diferenciando apenas que uma está sobre esteios e a outra sobre boias que a fazem flutuar acompanhando o nível das águas, que nessa região mudam sua cota drasticamente. Os flutuantes são casas mais próprias dessa região devido ao Açacu ser uma árvore própria dessa região, pouco encontrada em áreas de terra firme.

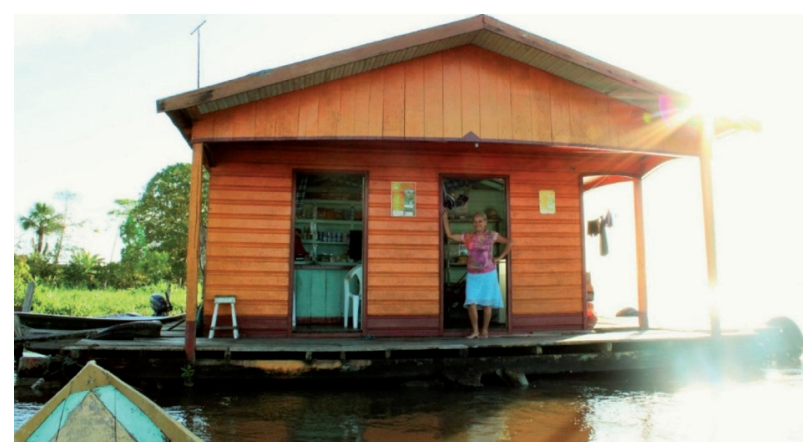

Figura 11: Flutuante 01. Miracauera, Careiro da Várzea, Laelia Nogueira, Julho de 2014.

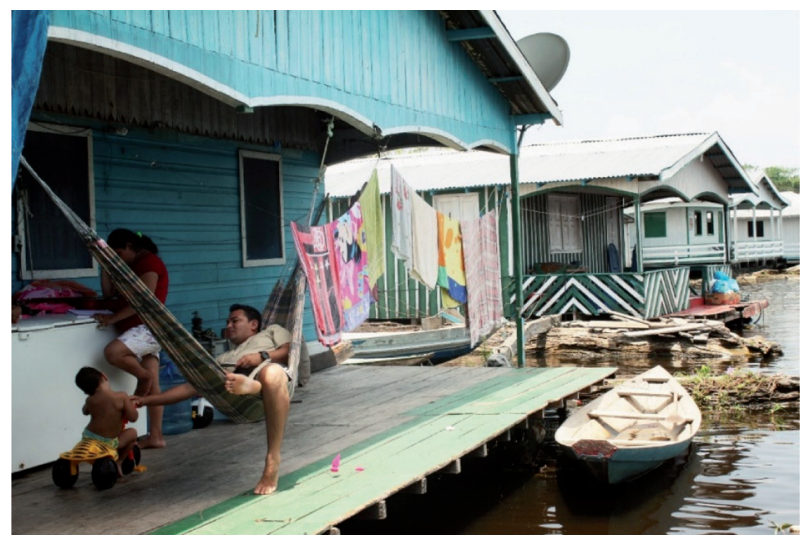

Figura 12: Casa flutuante, a vida sobre as águas. Fonte: Laelia Nogueira, 2015.

Esse é mais um exemplo de como a paisagem está ligada à maneira do homem de habitar, no Amazonas pode-se encontrar comunidades inteiras somente de flutuantes, onde, como na imagem a cima (Figura 12) a vida acontece sobre as águas, banzeiros e barcos. 


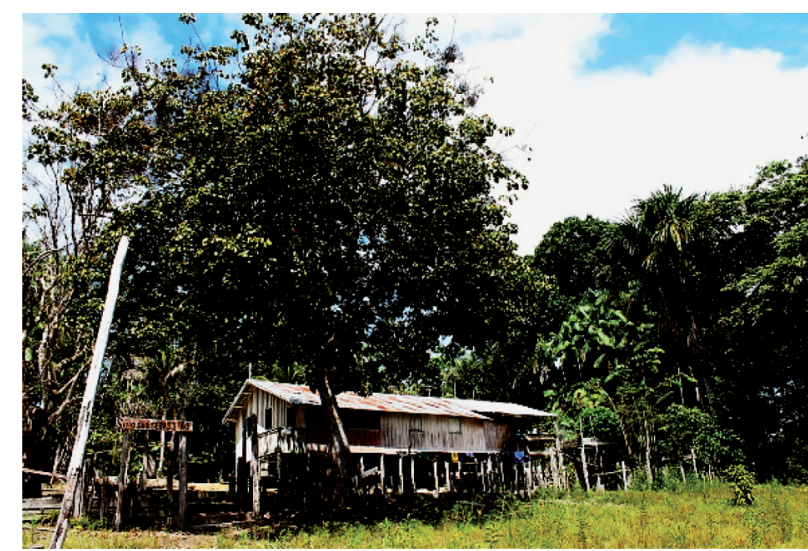

Figura 13: Casa de terra firme. Fonte: Laelia Nogueira; Rio Cuieiras, período intermediário, janeiro 2014.

Além desses, podemos exemplificar a casa de terra firme (Figura 13). Como observamos na imagem a cima, a casa de terra firme possui a mesma simetria que a casa de várzea, porém percebemos que suas tábuas estão posicionadas na vertical. Assim como na várzea isso representa a compra da madeira, na terra-firme representa sua extração. Nessa região, boa parte da população ainda vive de extrativismo conhecendo, portanto, os mais diversos tipos de plantas da região e sabendo exatamente quais as melhores propriedades de cada uma delas e quais devem ser usadas em quais partes que compõe a casa como descrito por seu Chiquinho, morador de uma comunidade no rio Cuieras:

Vou lhe dizer certinho, a senhora anota aí: a gente vai fazer uma casa por 6x12 (metros) mais ou menos: 12 esteios de sapucaia, que é um tipo de castanha, os tamanhos são $12 x 8 \mathrm{~cm}$ por 5 metros de comprimento mais ou menos porque elas vão até lá no alto da casa, e mais uma dessas para fazer 24 barrotes, que vão sustentar o piso. Essa madeira é boa para isso porque ela não apodrece a parte enterrada. Muito difícil precisar trocar. Usa o amarelão, que é um tipo dum louro, para fazer a amarração da casa, que são nove peças de 12 metros de $15 \times 10 \mathrm{~cm}$. Duas dúzias de perna manca de 6 metros de $8 \times 5 \mathrm{~cm}$ para o piso, dá uns $\mathrm{R} \$ 60,00$ a dúzia, e mais umas três dúzias de ripão pra ser o apoio pro telhado, de $6 \mathrm{~m}$ e $8 \times 3 \mathrm{~cm}$. Mais duas dúzias de caibro de $4 \mathrm{~m}$ por $8 \times 5 \mathrm{~cm}$ e mais quatro dúzias pro gradeamento das paredes. Pro piso a gente pode usar a cupiúba. Umas dez dúzias de tábuas dão. 20x3cme 4 metros de comprimento. Sai uns R\$150,00 a dúzia. Depois deixar bem lixadinho e passa cera de abelha, ai ele fica brilhoso. As paredes podem usar o louro preto, é uns R\$ 40,00 a dúzia. Usa umas 30 dúzias, e mais 20 dúzias de ripinha. Leva uns quinze dias para fazer se pegar direto. A gente faz primeiro a armação e o teto para nós não trabalhar no sol, precisa de umas 109 telhas e uns $30 \mathrm{~kg}$ de prego. (Seu Chiquinho em entrevista, 2015)

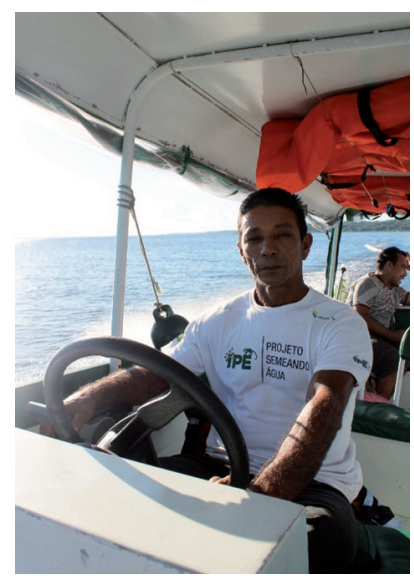

Figura 14: Seu

Chiquinho.

Fonte: Laelia Nogueira, 2015.

Diferente da casa de várzea, a casa de terra firme descrita a cima, é muito mais estável e sua durabilidade é uma de uma vida inteira. É comum ouvir falar de casas com mais de trinta anos, das quais jamais tiveram de ser trocadas uma peça se quer. Aqui as terras não caem. Cruls descreve a terra firme:

Tal como no rio Negro, rio de águas pretas que poderia ser tomado como padrão, a floresta não se faz anunciar. Chega logo a beira da água e apresenta-se sem rebuços. Não se pense, porém que por vir assim, tão prontamente, ao nosso encontro, tenha um ar mais prazeroso e comunicativo. Muito pelo contrário, de um verde tristonho carregado, essa mata de arvores não muito altas e folhagem miúda, tem um rosto bastante severo, trai qualquer coisa de sombrio e misterioso. Isso não impedirá, entretanto, que, de vez em quando, sobre o seu manto austero apareça qualquer mancha colorida. Azul neste ponto, amarela em outro. Rosa aqui, vermelha ali, roxa acolá. São frondes que entre frondes, que se diriam sempre iguais, abrem os seus vistosos baldaquinos floridos, porque, no dizer de Adolpho Ducke, não haverá, em toda a Hileia região que se lhe compare (referindo-nos sempre a bacia do rio Negro) na riqueza de árvores da mais deslumbrante floração. (CRULS, 1976. p. 14)

Dessa maneira as casas são compostas em geral por uma nave retangular com poucos cômodos, podendo variar das condições econômicas de cada morador, com um píer de apoio para receber a embarcação, ou uma varanda que também auxilia essa função. Cores sempre vivas e em geral com composições feitas com duas cores bastante contrastantes entre si, destacam-se do verde-eterno da floresta, descrito a cima. Assim nessa relação de troca, o homem e seu meio vão se alinhando e se construindo em conjunto.

Internamente, seja na casa de várzea ou na casa de terra firme, ambas possuem poucos móveis e apresentam um ar de "casa de vó": panelas bem areadas, cheiro de comida sendo feita, e sempre pronta para receber quan- 
tos convidados forem possíveis, sendo a cozinha muitas vezes o coração quente da casa.

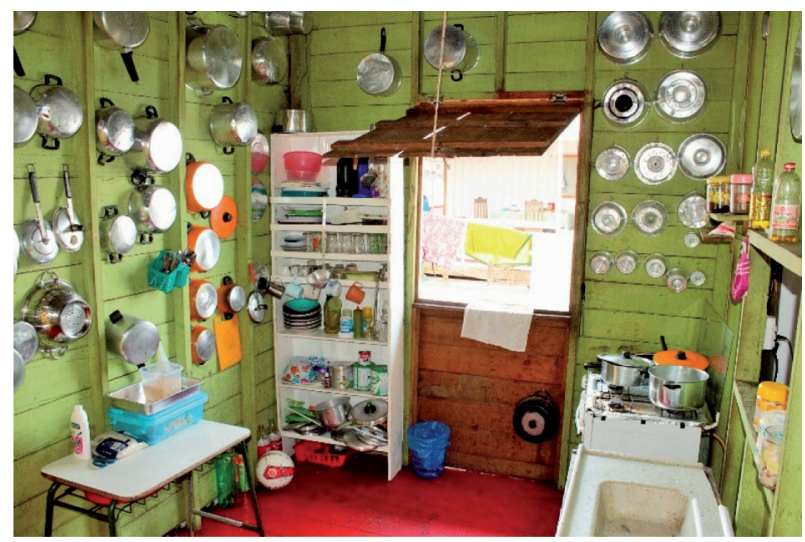

Figura 15: Cozinha do flutuante da dona Raimunda. Encontro das águas Laelia Nogueira, Setembro de 2014.

O piso é de extrema polidez e a quantidade de redes abundante, em geral recebem tratamento com cera de abelha e duram incontáveis dias. O jiral, constitui-se em uma das maiores marcas da casa ribeirinha, é por ele que a paisagem invade a casa, e permite ao morador um momento diário de contemplação. Essa abertura, em geral localiza-se na cozinha e é utilizado como bancada de pia, onde se lava a louça e se trata o peixe.

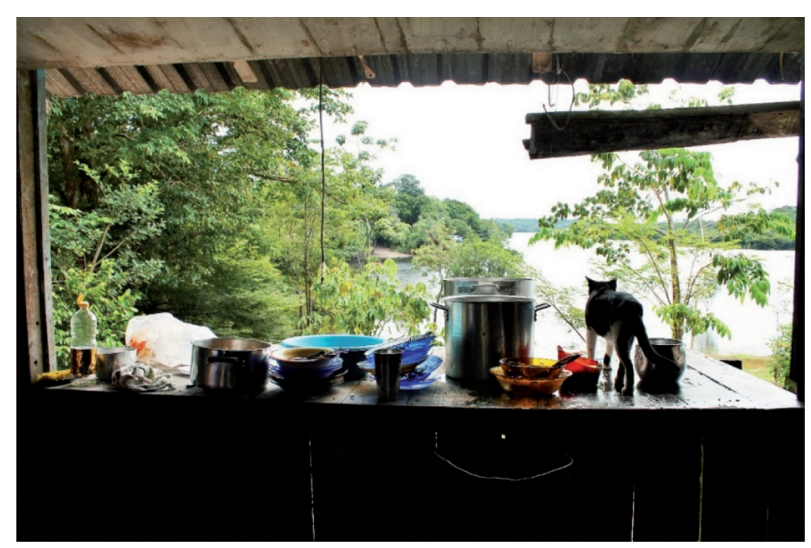

Figura 16: O Jirau; Rio Cuieras. Foto: Laelia Nogueira, Janeiro de 2014. Esse espaço é sem dúvida um dos mais interessantes das casas. Essa área de lavagem, é uma linda abertura para o lado externo da casa, representando juntamente com as varandas a ligação entre interior e exterior.

Durante a pesquisa, também fomos questionados pela dona Inês, moradora do Cuieras, sobre o porquê estaríamos fazendo uma pesquisa sobre "casa de pobre”. Minha visão era diferente da dela: para mim sua casa vale muito - disse eu - mais que muitas casas ricas. Elas não têm essa paisagem diariamente e nem estão aqui.

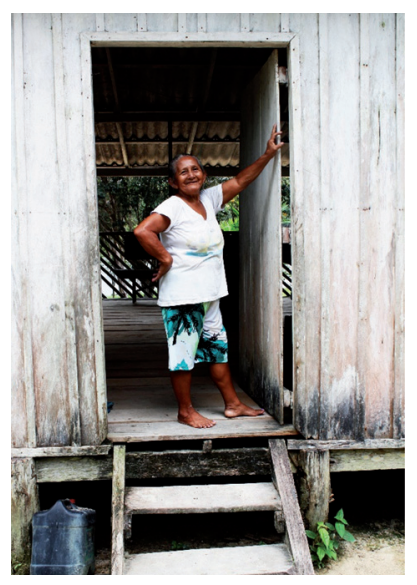

Figura 17: Dona Inês. Fonte: Laelia Nogueira, 2015 .

A paisagem a qual me refiro quando falo de dona Inês é a imagem a baixo:

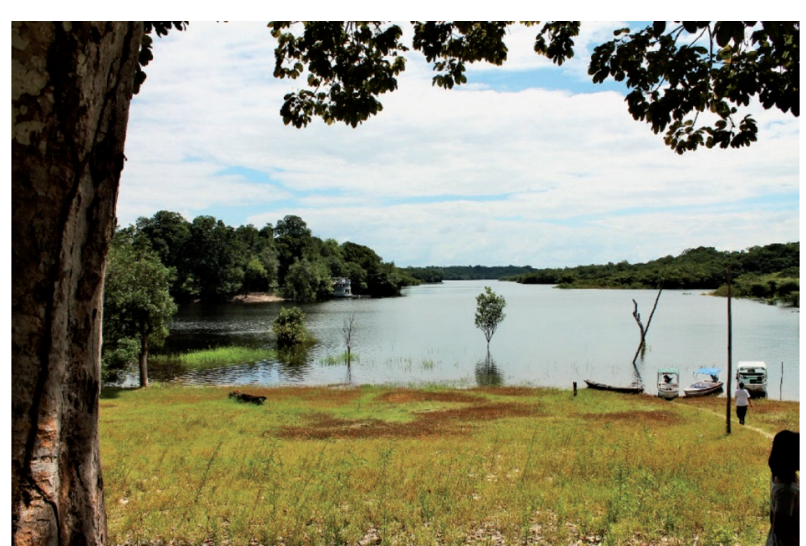

Figura 18: Frente da casa de dona Inês. Fonte: Laelia Nogueira, 2015.

Baseado na experiência do habitar ribeirinho pode-se perceber que a noção de casa perpassa todas as culturas e tradições, refletindo a própria cultura que a criou. No ambiente doméstico, vemos expostos diversos valores sociais. A manutenção e transmissão de tradições também se inicia na casa. Na casa nascemos, crescemos e morremos. Nela "o passado, o presente e o futuro dão à casa dinamismos diferentes, dinamismos que frequentemente intervém, as vezes se opondo, as vezes estimulando-se um ao outro" (BACHELARD, 1996). Ainda no intuito de demonstrar a importância da casa para o ser, podemos colocar que:

Sem ela (a casa), o homem seria um ser disperso. Ela mantém o homem através das tempestades do céu e das tempestades da vida. Ela é corpo e alma. É o primeiro mundo do ser humano. Antes de ser "atirado ao mundo", como professam os metafísicos apressados, o homem é colocado no berço da casa. (...) A vida começa bem; começa fechada, protegida, agasalhada no seio da casa. (BACHELARD, p. 201, 1978)

Podemos a partir daí buscar uma "fenomenologia da casa", ou "fenomenologia dos espaços" construídos, onde 
"A arquitetura pertence à poesia, e seu propósito é ajudar o homem a habitar" (NORBERG-SHULZ, p. 459, 2013) é ela que dá suporte, embasa e reúne todas as essências desse habitar ribeirinho, segundo a quadratura, que se manifesta na construção da casa e na manutenção da vida.

Os lugares construídos pelo homem se relacionam com a natureza de três formas básicas. Em primeiro lugar, o homem deseja fazer a estrutura natural mais exata. Isto é, ele quer visualizar seu "modo de entender" a natureza, dando expressão à base de apoio existencial que conquistou. Para tanto, ele constrói o que viu: onde a natureza insinua um espaço delimitado, constrói uma área fechada; onde a natureza se mostra “centralizada”, ele erige um Mal [marco]; onde a natureza indica uma direção, ele faz um caminho. Em segundo lugar, o homem tem de simbolizar seu modo de entender a natureza (inclusive ele mesmo). A simbolização implica "traduzir" para outro meio um significado experimentado. Por exemplo, um determinado caráter natural é traduzido em uma construção cujas propriedades de algum modo o exprimem. O objetivo da simbolização é libertar o significado da situação imediata, por meio do que se torna um “objeto cultural”, que pode fazer parte de uma situação mais complexa ou transferir-se para outro lugar. Finalmente, o homem precisa reunir os significados apreendidos por experiência a fim de criar para si mesmo uma imagino mundi ou um microcosmo, que dê concretude a esse mundo. A reunião desses significados depende, é claro da simbolização e pressupõe uma transposição de sentidos para algum lugar, que por isso assume o caráter de um "centro" existencial. (NORBERG-SHULZ, p. 453, 2013)

Na origem do habitar ribeirinho está o embalar das redes e dos banzeiros. O rio, elemento de tão grande importância, como descreve Eidorfe Moreira, é, talvez até mesmo antes da terra, o elemento mais marcante da paisagem amazônica, através dos seus "per-cursos" como propõe Lúcia Gratão (2002), a vida se conserva.

Como um poderoso imã liquido, ele submete à sua gravitação todos os aspectos da vida regional, de tal modo que não podemos estudar a região, sob qualquer ponto de vista que seja, sem o prévio reconhecimento da importância do elemento liquido como base desse estudo e consideração. (MOREIRA, p. 63, 1960)

A paisagem toma conta. Invade o ser. A exuberância amazônica é tamanha que nos sentimos pequenos e impotentes mediante ao seu tamanho. A presença dessa paisagem que aqui tentamos retratar a partir do cotidiano amazônico, busca demonstrar como a relação cotidiana com o meio interfere em nossos modos de fazer, podendo esse fato ser percebido em qualquer outra cultura, onde a estética material está completamente atrelada a valores adquiridos pela paisagem, que são expressos materialmente através de utensílios-ferramentas-coisas, remetendo a Heidegger (2011) quando ele diz "Em habitando os mortais são". "A maneira como eu sou e como tu és homem sobre essa terra é o buan, o habitar." (HEIDEGGER, 2011) Um habitar repleto de conhecimento e experiências. Experiências que atravessam os tempos e que demonstram um grande conhecimento do lugar que os cerca: "Eu sou. Tu és. Nós somos afluente desse rio - medula do universo que nasce no infinito e desemboca no âmago do Ser que somos parte" (Siqueira, sem Data).

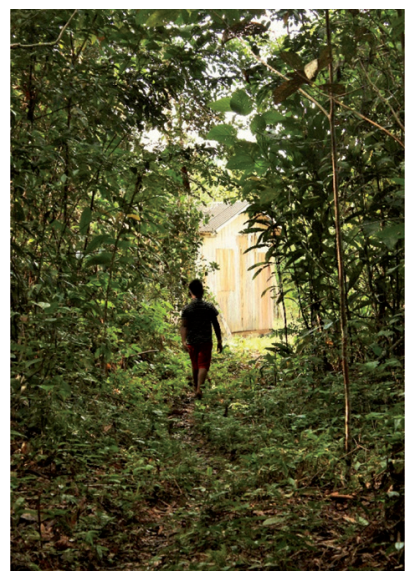

Figura 19: Verde vagomundo. Título da obra de Beneticto Monteiro, capturada através dessa fotografia. Busca demonstrar a imersão e imensidão do e no mundo amazônico. Fonte: Laelia Nogueira, 2015.

\section{Considerações finais}

Ao ver esses exemplos, devemos pensar em como perpetuar e não deixar que esses conhecimentos tradicionais se percam. Eles devem ser valorizados e transmitidos. Para saber ver o mundo com mais clareza é necessário experienciá-lo. Devemos, portanto, perceber a possibilidade de quebras de paradigmas que pesquisadores fenomenólogos têm nas mãos: demonstrar que o mundo que o mundo a nossa volta acontece de maneira fluida como os rios, que é possível nos desprender das dualidades do mundo positivista, a partir do momento que percebemos o mundo da vida e que com ele travamos uma relação de cumplicidade extremamente profunda.

O habitar dessa população é extremamente inspirador, pois demonstra outra valorização do mundo a nossa volta onde o aprendizado através dele é independente de formalidades como as que estamos submetidos, além de ser indispensável para a própria sobrevivência. A casa ribeirinha carrega consigo uma herança extremamente valiosa, que é a expressão de toda uma cultura. Assim como as demais casas típicas feitas pelos mais diversos povos através dos tempos, que ensinam e contam histórias, não só coletivamente, mas também as histórias individuais de cada um.

Habitamos sob diversos elementos que contextualizam nosso habitar. Foi possível ver isso através do entendimento da quadratura de Heidegger apresentada anteriormente, 
demonstrando que o trabalho fenomenológico empírico pode ser extremamente rico, podendo perceber a teoria funcionando na prática muito claramente, sendo possível compreender as relações homem-mundo apresentadas por diversos autores. Terra, céu, mortais e divino se interligando através da ponte, aqui representada pela a casa. A casa como ligação e elo entre as pontas. A casa está no entre; do útero é a placenta.

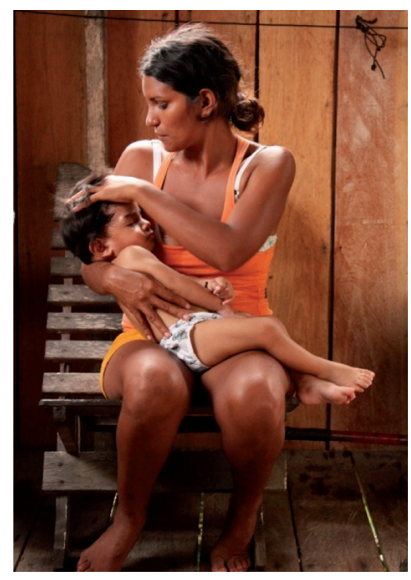

Figura 20: Mãe-casa.

Foto: Laelia Nogueira, 2015.

\section{Referências}

Bachelard, G. (1996). A poética do espaço. São Paulo, Martins Fontes.

Cosgrove, D. (1998). A geografia está em toda parte. In Paisagem, tempo e cultura. Organizadores Roberto lobato Correa, Zeny Rosendahl, Rio de Janeiro Ed. UERJ.

Cruls, G. (1976). Hiléia Amazônica. Aspectos da flora, fauna, arqueologia e etnografia indígenas. 4. ed. Rio de Janeiro, Livraria José Olímpio Editora/MEC.

Cruz, Manuel de Jesus Masulo da. (2009). Campesinato e meio ambiente na várzea da Amazônia. In: MEDEIROS, R. M. V. e FALCADE, I. (Org.) Tradição Versus tecnologia: as nova territorialidades do espaço brasileiro. Porto Alegre. Editora da UFRGS, p. 143-170.

Cunha, E. (2011). Amazônia: um paraíso perdido. Manaus, Editora Valer.

Dardel, E. (2011). O homem e a terra: natureza e realidade geográfica. Tradução Werther Holzer. São Paulo, Perspectiva.

Gratão, L. H. B. (2002). A poética d'o rio-Araguaia! De cheias...e... vazantes... (à) Luz da imaginação. Tese (Doutorado em Geografia), Universidade de São Paulo, São Paulo.

Heidegger, M. (2001). Ensaios e conferencias. Petrópolis, RJ: Vozes.

Holzer, W. \& Alcantara, V. (2008). Paisagem vernacular: aldeamentos salineiros. Revista Poiésis, n. 12, p. 89-100, nov.

Loureiro, J. J. P. (1994) Cultura amazônica: uma poética do imaginário. Belém, CEJUP. Melo, T. de. (2003). Amazonas: no coração encantado da floresta. Ilustração: Andrés Sandoval. São Paulo: Cosac Naify.
Monteiro, B. (1974) Verde Vagomundo. Rio de Janeiro, Marco zero: PLG Comunicações.

Merleu-ponty, M. (1994) Fenomenologia da percepção. São Paulo, Martins Fontes.

Moreria, E. (1960) Amazônia: o conceito e a paisagem. Coleção Araújo Lima. Agência da SPVEA, Rio de Janeiro.

Nogueira, A. R. B. (2014) Percepção e representação geográfica: a geografia nos mapas mentais dos comandantes de embarcações no Amazonas. Manaus, Edua.

Norberg-Schulz, C. (1995) O fenômeno do lugar. In: Uma nova agenda para a arquitetura. Organização Kate Nesbitt. São Paulo: Cosac Naif.

Rangel, A. (2008) Inferno Verde: cenas e cenários do Amazonas. Manaus: Editora Valer.

Siqueira, J. (s/d). A margem oculta. Poema para Benedito Monteiro. Disponível em: <http://benedictomonteiro.blogspot.com. br/2010/12/margem-oculta-poema-de-juraci-siqueira.html>.

Tuan, Yi-Fu. (2013). Espaço e lugar: a perspectiva da experiência. Tradução Lívia de Oliveira, Londrina, Eduel.

Laelia Regina Batista Nogueira - Mestre em arquitetura e urbanismo pela Universidade Federal Fluminense, graduada em arquitetura e urbanismo pela Universidade Luterana do Brasil (2013) e graduação em Design e expressão gráfica pela Universidade Federal do Amazonas (2011). Endereço: Rua Visconde de Laguna, casa 203, condomínio Anavilhanas - Bairro: Parque das Laranjeiras - CEP: 69058-750 - Manaus - Amazonas. E-mail: laelia.design@gmail.com

Recebido em 26.04.16 Primeira Decisão Editorial em 29.08.16 Aceito em 11.09.16 